\title{
Active life expectancy and functional limitations among older Cambodians: Results from a 2004 survey
}

Zachary Zimmer

Population Council

Follow this and additional works at: https://knowledgecommons.popcouncil.org/departments_sbsr-pgy

Part of the Demography, Population, and Ecology Commons, Gerontology Commons, and the International Public Health Commons

How does access to this work benefit you? Let us know!

\section{Recommended Citation}

Zimmer, Zachary. 2005. "Active life expectancy and functional limitations among older Cambodians: Results from a 2004 survey," Policy Research Division Working Paper no. 201. New York: Population Council. 


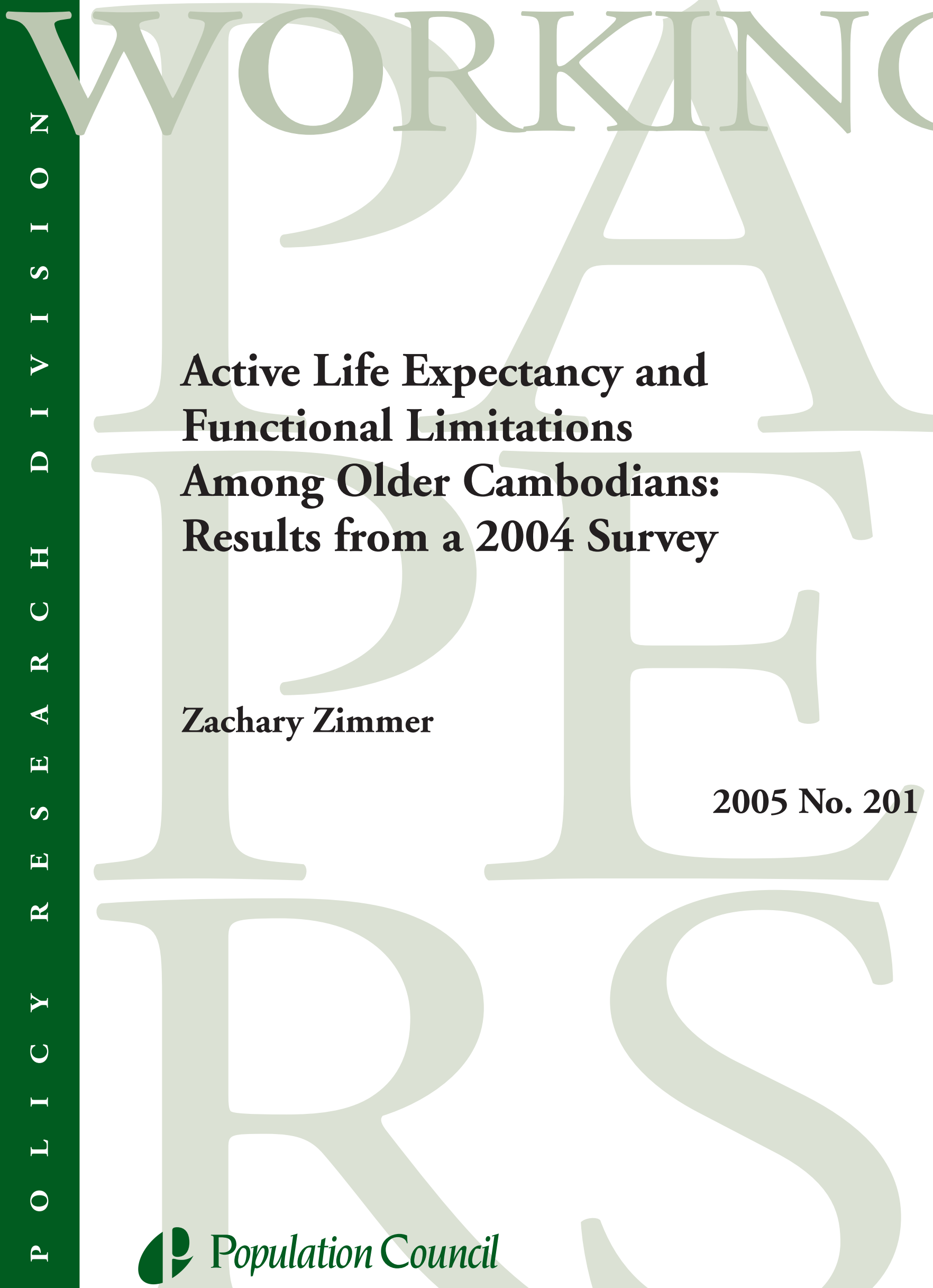




\section{(P) Population Council}

One Dag Hammarskjold Plaza

New York, New York 10017 USA

www.popcouncil.org

pubinfo@popcouncil.org

This material may not be reproduced without written permission from the author. For a list of Policy Research Division Working Papers, including those that are currently available for downloading in PDF format, see www.popcouncil.org/publications/wp/prd/rdwplist.html.

ISSN: $1554-8538$

(C) 2005 The Population Council, Inc. 


\title{
Active Life Expectancy and Functional Limitations Among Older Cambodians: Results from a 2004 Survey
}

\author{
Zachary Zimmer
}

An earlier version of this paper was presented the annual meeting of the International Network on Health Expectancy and the Disability Process (REVES) in May 2005. This research was supported by grants from the National Institute on Aging (sub p/g F009700, sub p/g F010799, R01 AG20063-01) and UNFPA Cambodia. 


\begin{abstract}
This study's aims are to: 1) determine the prevalence of functional limitations among older adults in Cambodia using activities of daily living (ADLs); 2) compare limitation prevalence with other countries in the region; 3) estimate active life expectancy; 4) examine standard correlates of functional status and assess whether they are associated with limitation in expected ways. ADLs included here are bathing, dressing, eating, and getting up from lying down. Degree of difficulty is used to determine whether limitations are moderate or severe. Results are generally consistent with expectations. For example, women live longer than men but spend a greater proportion of life with limitations, and older age is related to higher rates of limitation and less active life. Elderly Cambodians appear more likely to report limitations than their counterparts in neighboring countries. A contribution of the analysis is the examination of a basic measure of health among a population that until recently has been isolated from the rest of the world.
\end{abstract}


Older adults in Cambodia have faced a history of traumatic circumstances, having survived decades of political and social volatility, including civil war, revolution, genocide, mass migration, and occupation by neighboring states (Ea 1981; Heuveline 1998; Huguet 1991; Keirnan 2002, 1996). According to survivor accounts, the period between 1975 and 1979, when the Pol Pot-led Khmer Rouge held power throughout the country, was particularly brutal (Chan 2004; Ung 2000). During this period, excess mortality due to violence, famine, and disease was substantial (Ea 1981; Heuveline 1998; Keirnan 2003; Neupert and Prum 2003). Although more peaceful conditions have prevailed over the last decade, living conditions remain difficult. The country is struggling economically, poverty is widespread, health care resources are underdeveloped and underfunded, roads and other infrastructure are in poor condition, literacy rates are low, and HIV/AIDS prevalence rates are high (Annear 1998; Huguet et al. 2000; Kola 2004; Ott 1997).

Data on the health status of older adults living in such extreme conditions are not readily available, and investigations into long-term health effects of traumatic circumstances are rare. Yet it is not difficult to imagine that the past conflict and violence experienced in Cambodia, coupled with current harsh living conditions, would have deleterious effects on the health of its older population. Some examinations in other parts of the world have linked war and violence to stress, anxiety, depression, and other mental health problems, which may subsequently contribute to the development of chronic health and functional disorders (Butera, Bultinck, and Mercier 1999; Farhood et al. 1993; Pedersen 2002). Although a relationship between conflict and health has not been established specifically within Cambodia, refugees living on the Thailand border have been shown to suffer disproportionately from a variety of health problems (Mollica et al. 1993). More broadly, the violence and conflict that have been experienced in Cambodia impinge on the ability to develop health services, thus reducing access to health resources for citizens (Agudelo 1992; Ityavyar and Ogba 1989; Lanjouw, Macrae, and Zwi 1999). Moreover, the current lack of infrastructure and the impoverished circumstances facing many older adults may be inhibiting access to health care because of the lack of both available facilities and sufficient income to pay for services.

War and violence can affect the health of families in a number of ways. First, they impose stress within family relationships (Schwab et al. 1995). Second, the excess adult mortality that occurs during times of conflict and violence deprives older adults of family members on whom they can rely for social support. Third, the separation of families due to war may have had long-term effects on cohesion, integration, and intergenerational support. Finally, it is conceivable that an alternate relationship exists between conflict and later-life health whereby the probability of surviving is related to a particular robustness that also confers protection from health disorders later in life.

The lack of data about the health status of older Cambodians is a consequence of the country's long period of isolation from the rest of the world and the elimination of academic institutions in the 1970s by the Khmer Rouge (Chandler 2000; Huguet 1991). Universities are now being reestablished in Cambodia, and government and nongovernmental agencies have recently collected some social and demographic data, including a 1998 census, a Demographic and Health Survey in 2000, and several 
socioeconomic surveys conducted by the National Institute of Statistics (National Institute of Statistics, Directorate General for Health [Cambodia], and ORC Macro 2000; Huguet et al. 2000; National Institute of Statistics 1997). The current study relies on the 2004 Survey of the Elderly in Cambodia. This survey, the first of its kind, employs a representative sample of adults aged 60 and older living throughout Cambodia. The project that generated the survey is a joint effort between the University of Michigan, the Population Council, and the Royal University of Phnom Penh. One of its goals is to provide much-needed information on the health conditions of Cambodia's elderly population. The analysis provided here presents some basic descriptive, comparative, and explanatory findings.

The current study has several aims. First, it examines survey responses to a series of items related to activities of daily living (ADL). ADLs are functioning tasks necessary for self-maintenance and daily survival; an inability to conduct an ADL can be classified as a functional limitation. Second, it compares these with prevalence rates found from surveys conducted in other Southeast Asian countries. Third, ADLs are employed to estimate years of active life expectancy (ALE). Finally, correlates of ADL limitations are examined via multivariate equations using a small number of standard demographic predictors. Specifically, previous research across a number of populations has suggested that younger age, being male, being married, and having higher socioeconomic status (for example, having high levels of education and income) are associated with a lower likelihood of reporting a functional limitation (Crimmins, Hayward, and Saito 1996; House et al. 1990; Kaplan 1992; Manton 1989; Melzer et al. 2001; Pol and Thomas 1992; Preston and Taubman 1994; Rogers, Rogers, and Belanger 1992; Strawbridge et al. 1992; Zimmer et al. 2002). In the developed world, particularly the United States, rural residence has been shown to be associated with better health outcomes (Gillanders, Buss, and Hofstetter 1996; Verheij 1996). Since urbanites generally have higher socioeconomic status and better access to health care, this finding presents a paradox. But the finding is often attributed to the stronger social cohesion and family integration and higher levels of social support found in rural areas. The situation in developing countries is less clear, in part due to a lack of empirical research on the topic (Harpham et al. 2003). In general, urban dwellers in developing countries have higher socioeconomic status and much better access to health care, although there is also evidence that some chronic health disorders related to lifestyles, such as heart disease and diabetes, are on the rise in rapidly developing urban areas. Rural areas in Cambodia are lacking in health infrastructure, a circumstance that quite likely influences health outcomes, such as functional status. These factors (age, sex, marital status, socioeconomic status, and urban/rural residence) represent some of the most important demographic correlates of functional status, and the present analysis will examine them to ascertain whether they are related to the health status of the Cambodian elderly population in expected ways.

\section{FUNCTIONAL LIMITATION AND ACTIVE LIFE EXPECTANCY}

According to a popular conceptualization of disablement, disability refers to the loss

of capacity to carry out usual and necessary functional tasks that allow individuals to maintain themselves within a given environment, such as rising from bed or shopping for 
food (Deeg, Verbrugge, and Jagger 2003; Verbrugge and Jette 1994; World Health Organization 1990). Functional status refers to the ability to perform tasks that are necessary within a particular environment, and a functional limitation can be considered as a gap between physical ability and the demands of the environment (Verbrugge and Jette 1994). For instance, in order to rise from bed, an individual must have a certain physical capacity, but the type of bed one sleeps in may influence performance. An individual in a poor country who sleeps on a mat on a hard floor may be more functionally limited than an individual in a developed country who sleeps on a raised bed. Subsequently, the individual sleeping on a mat on a floor may have a greater need for assistance than does another individual with similar physical abilities. Functional tasks such as shopping for food may involve a larger array of environmental circumstances, such as the location of a market and the condition of infrastructure like transportation and road conditions. Because functional status refers to the ability to perform necessary tasks, it is a principal indicator of wellbeing, and accordingly is an excellent starting point for evaluating the health of an older population of which little is known.

The current analysis employs ADLs, a standard set of functional status items that are obtained through self-reports on surveys (Katz et al. 1963). These are functional tasks necessary for self-maintenance. The inability to perform one of these tasks is defined as a functional limitation. ADLs have been used in numerous surveys among many types of populations. The 2004 Cambodian survey includes four common ADLs-getting up from lying down, eating, bathing, and dressing - all of which are used in the current study.

Active life expectancy (ALE) refers to the number of years an individual can expect to live without functional limitations such as those measured using ADL (Katz et al. 1983). It combines information on functional status and mortality and is unaffected by the age structure of a population; thus, it is an ideal tool for comparing the health of different population groups, such as males versus females. ALE is becoming widely used in international research and, therefore, estimates obtained from one population can be readily compared with others (Mathers 2002; Saito, Crimmins, and Hayward 1999; Saito, Qiao, and Jitapunkul 2003). In addition to examining expected life without limitations, ALE can also assess expected life in a variety of functional states, such as without any functional limitations, with moderate limitations, or with severe limitations.

\section{METHODS}

\section{The 2004 survey of the elderly in Cambodia}

Between April and October 2004, a sample of 1,273 randomly selected adults aged 60 and older living throughout Cambodia were interviewed. The survey was designed to determine: 1) the living conditions and economic, social, and physical well-being of older adults and their families; 2) their health and material needs; 3) the impact of Cambodia's turbulent history on their current situation; and 4) the impact of the AIDS epidemic on older adults as parents of offspring who succumbed to the disease. Interviews were conducted in the homes of older adults by students and staff from the Royal University of Phnom Penh. The survey took about one hour to complete and yielded extensive data on the abovementioned topics. In a very small number of cases where older adults were incapable of 
responding to questionnaire items, the surveys were completed using a family member as a proxy.

A multiple-stage systematic probability sample was conducted in two steps, the first in Phnom Penh and the second in other provinces. Of Cambodia's 24 provinces, six were chosen for the study. These six provinces are the highest populated and include over 50 percent of the country's population: Battambang, Kampong Cham, Kandal, Phnom Penh, Prey Veng, and Takeo. Within Phnom Penh province, administrative villages were chosen using a listing provided by the National Institute of Statistics (2000). Within each village there was a random selection of two enumeration areas. Interviewers were first sent to the enumeration areas to identify households containing an older adult. Staff from the Ministry of Planning in Phnom Penh assisted by providing maps of enumeration areas and training for the interviewers. Several weeks later, interviewers returned to randomly selected households to conduct an interview. Within the five other provinces, sampling involved first a systematic selection of districts, then communes within districts, and finally villages within communes. Once villages were selected, the sampling procedure continued in the same fashion as in Phnom Penh.

The total sample is over-represented in Phnom Penh, so a weighting procedure is used to adjust. The final weighted sample is representative of the six provinces. Since only one person per household was interviewed, those living in households with a single older adult have a higher probability of being selected than households with two or more older people. Therefore, an additional weight adjusted for the number of older adults living within households. Analysis was performed to determine whether the weighted sample matched other representative surveys in Cambodia, such as the 1998 census, the 2004 Intercensal survey, and the 2000 Demographic and Health Survey, and the current sample was found to be similar with respect to basic demographic characteristics. More information on the survey, sampling, and weighting is provided in Knodel et al. (2005).

\section{Measures}

The current analysis focuses on four activities of daily living. Specifically, respondents were asked whether they had any difficulty eating, bathing, dressing, and getting up from lying down. In addition, if a difficulty was reported, individuals were asked whether they had a little difficulty, a lot of difficulty, or so much difficulty that they could not conduct the task at all. I define the reporting of a difficulty of any severity as a functional limitation. In the analysis that follows, I report the percent who have a limitation with at least one of the four items and with specific items. I also refer to the percent reporting severe limitations, defined as having a lot of difficulty or being unable to conduct a task.

A Cronbach's alpha reliability test on the four ADLs yields the value .769. A principal components factor analysis shows that the four load highly onto a single factor, with a 2.495 eigenvalue explaining 62.4 percent of the variance. A correlation matrix shows correlation coefficients between items ranging from .45 to .80 . Hence, the four are well associated, although they are not completely correlated. 
For multivariate equations, I examine several correlates. Age is a continuous variable in multivariate models, although it will be categorized for descriptive analyses. Sex is coded as female versus male and marital status as married versus not married. Place of residence is coded as either rural or urban, based on the Ministry of Planning classification of the village of residence (National Institute of Statistics 2000). Two indicators of socioeconomic status are literacy and income satisfaction. Literacy is a threecategory measure created from a question on ability to read, with categories illiterate, somewhat literate (those who can read but not well), and literate. Reliable measures of income are difficult to obtain from older adults in Cambodia, so a replacement for actual income is a survey item that asked respondents whether they were satisfied with their current income. A four-category measure includes being unsatisfied, somewhat satisfied, satisfied, and having missing data. The last category is included because of a fairly high number of missing responses for this item (3 percent), likely the result of proxy respondents. Table 1 presents distributions for these covariates by sex, with p-values provided to show whether the distributions differ by sex.

\section{Analysis}

I begin by reporting limitation prevalence rates for individual activities of daily living and for combinations of ADLs. I then compare the prevalence of specific ADL limitations with rates reported from other surveys conducted in the region. Next I calculate active life expectancy. This requires division of the sample into various functioning states. Using terminology that is common in ALE analyses, I define an active state as being able to perform all four ADLs, or having no functional limitation, and an inactive state as having a limitation with at least one of the four. Further, I subdivide inactive into having moderate or severe limitation. Respondents with moderate limitation report a little difficulty with tasks, and those with severe limitation report a lot of difficulty or they are unable to conduct a task.

Calculations of ALE can be based on prevalence-based life tables when only crosssectional data are available, or on multi-state life tables when panel data are available. The current calculation is limited to the former, commonly referred to as the Sullivan method (Sullivan 1971). The Sullivan calculation indicates the functional status of a population adjusted for mortality (Laditka and Hayward 2003; Saito, Crimmins, and Hayward 1999). It decomposes life expectancy into life remaining in various functional states, determined by applying prevalence rates for functional limitation to an Lx column of a life table (Jagger 1999). The result is an additional life table column that assigns person-years lived in various states of functioning. For the current study, prevalence rates by age and sex are determined from the 2004 survey of the elderly in Cambodia. Prevalence rates increase linearly with age, although there is some stochastic variation, and females report higher prevalence than males. Preliminary analyses showed no significant age-by-sex interaction. Therefore, the most useful estimation of ALE comes from the smoothing of prevalence rates by age and sex using a maximum likelihood procedure that regresses functional limitation probabilities on age and sex. The variances of prevalence rates are then used to 
determine standard errors and confidence intervals for the ALE estimates (Jagger 1999). I use an abridged life table from the National Institute of Statistics (2004).

Finally, I employ logistic regression equations to examine demographic correlates of functional limitation. Here I present the odds of reporting individual ADL limitations, any limitation, and any severe limitation, by age, sex, marital status, literacy, satisfaction with income, and rural/urban residence.

\section{RESULTS}

\section{ADL limitation prevalence rates}

Table 2 shows prevalence rates for limitations using the four ADLs included in the survey and rates for similar items obtained from surveys of older adults conducted between 1989 and 1996 in four other Southeast Asian countries - Burma, Indonesia, Philippines, and Thailand. In addition, the percent reporting at least one of the limitations is included. Item wording is generally comparable, but any differences are noted at the bottom of the table. Two of the other surveys (Philippines and Thailand) included people aged 50 and older, but I include only those 60 and older in the table. P-values obtained from difference in proportion tests are provided to show whether prevalence rates from the other four countries are statistically different from those found in the Cambodian survey. (Because the surveys from the Philippines and Thailand did not ask about getting up from lying down, the difference in proportion test for any limitations in Cambodia versus these two countries considers only eating, bathing, and dressing.)

For Cambodia, the highest prevalence for any single item is for getting up from lying down, with nearly 19 percent of older adults reporting a limitation. Many fewer have limitations eating ( 9 percent), bathing ( 8 percent), or dressing ( 6 percent). A similar item also has the highest prevalence in Burma and Indonesia, the only other surveys to ask about getting up from lying down, although the question in the latter two countries asked about getting up from bed. Similarly, dressing is the least frequently reported limitation in three of the four other surveys. However, the prevalence rates for each of the ADL limitations are higher in Cambodia than in any of the other four countries. In some cases, the differences are moderate. For instance, there is no statistically significant difference between Cambodia and the Philippines in the percent reporting bathing and dressing limitations. In other instances, Cambodian elders are much more likely to report limitations. For instance, only about one-third as many older adults in Indonesia and about one-half as many in Thailand report difficulties dressing.

I conducted additional analyses (not shown) to examine the structure of functional limitations. Those who reported only one of the four limitations were most likely to report problems getting up from lying down, but this tendency was not universal. About 16 percent of those reporting one limitation reported it to be eating, 8 percent bathing, and 1 percent dressing. Those who reported three of four limitations were most likely able to eat while being unable to conduct the other tasks. Still, between 10 percent and 20 percent of those able to do just one task reported that task to be either getting up from lying down, bathing, or dressing. Therefore, it is difficult to determine a hierarchy in this sample among the four ADLs. 
Table 3 examines prevalence rates by age and sex for individual limitations and for at least one of four ADL limitations. In addition, the top part of the table shows the percent having a limitation of any severity, while the bottom shows the percent having severe limitation.

Looking first at the prevalence of having a limitation of any severity, women have higher prevalence rates for each of the four tasks. About 19 percent of men report a limitation with at least one task, compared to about 26 percent of women. As for severe limitation, women again have higher prevalence rates. About 11 percent of women report at least one severe limitation, compared to about 7 percent of men.

The percent reporting limitations increases fairly linearly with age, both for any severity and for severe limitation. The exception is the 75-79-year-old group, who appear less likely to report a limitation than would be expected. For instance, the percent reporting limitation of any severity with at least one ADL increases from about 12 percent among those 60-64 all the way to 44 percent among those 80 and older, with increases of about 10 percentage points per age group, except for virtually no increase when moving from the 70 74-year-old group to the 75-79-year-old group. Similarly, the percent with at least one severe limitation increases from about 3 percent to about 22 percent from the youngest to the oldest age group, with the 75-79-year age group again being an anomaly. I can think of no particular reason that this age group does not follow the generally linear path, except for the stochastic qualities associated with small samples. For this reason, later analyses smooth results by considering age as a continuous measure.

The relationship between age, sex, and functional limitation is further highlighted in Figure 1, which plots the percent reporting any ADL limitation and any severe ADL limitation by the combination of age and sex. The figure shows a generally linear increase with age, with a few exceptions. It also shows men at each age group to be generally less likely to report ADL difficulties than women, and very little interaction between age and sex. The lowest prevalence occurs among 60-64-year-old men (6 percent report any and 2 percent report severe), and the highest among women aged 80 and older (53 percent report any and 24 percent report severe). It is curious that the leveling of prevalence rates at the 75-79-year age group is similar for both men and women and for both any and severe limitation.

\section{Active life expectancy}

Table 4 presents estimates of active life expectancy with 95 percent confidence intervals. The first column of numbers shows total expected years of life remaining by age group. The next two columns show the number of years expected without a limitation (i.e., active life) and the number of years expected without severe functional limitation. Subtracting these latter two columns from the total expected years of life results in the last two columns: years expected with limitations and years expected with severe limitations. For both men and women, years of active life decline with age. Men aged 60-64 live 11.87 of their remaining 15.02 years without any limitation and 13.77 years without a severe limitation. Therefore, they live 3.15 years with limitation, and 1.25 years with severe

limitation. Subtracting these last two numbers suggests that 1.90 years are spent with 
moderate limitation. The total active years and years without a severe limitation decline steadily with age, to 3.03 and 4.26 respectively for men 80 and older. Women aged 60-64 can expect 12.15 of their remaining 17.04 years of life to be spent without a limitation and 14.96 without a severe limitation. Therefore, they live 4.89 years with a limitation, 2.08 with a severe limitation, and 2.81 years with moderate limitation. Women's active years and years without a severe limitation decline with age to 2.91 and 4.48 respectively by age 80 and older.

Women, at each age, live longer than men, but there is less difference between the sexes in number of years without a limitation. For instance, men aged 60-64 can expect to live another 15.02 years, compared to 17.04 years for their female counterparts, a difference of about two years. But the female advantage in years without a limitation is merely about a third of a year, and the advantage in years without a severe limitation is a little over one year. The net result is that women live more years of life but also more years functionally limited. At age 60-64 a man can expect to live 3.15 years with a functional limitation, while the corresponding number for women is 4.89 . At age 80 and older, a man can expect 2.28 years with a limitation and 1.05 years with a severe limitation. The corresponding numbers for women at that age are 3.17 and 1.59 .

Figure 2 transposes the results into percent of remaining life expected in various states of functional limitation. For both men and women, increasing age brings increasing proportions of life in states of moderate and severe limitation. For instance, women aged 60-64 can expect to live about 70 percent of their remaining years without any limitation. By age 80 , less than half of their remaining years are spent without any limitation. The percent of time women spend with severe limitation increases steadily from about 15 percent at age 60-64 to about 25 percent by age 80 and older. Compared with men, women at each age can expect to spend a greater percentage of remaining life with any, with moderate, and with severe limitation. For instance, men at age 60-64 can expect about 80 percent of life, or about 10 percentage points more than women, to be spent in the active state, without any ADL limitations.

\section{Predictors of ADL limitation}

Finally, I turn to multivariate equations to examine some of the common demographic predictors of ADL limitation. I hypothesize that increasing age and being female increase the chances of having a functional limitation as measured by ADLs. We have already seen that this is the case among elderly Cambodians. I also assume that the unmarried, those living in rural areas, and those with lower literacy, education, and less satisfaction with income would be more likely to experience any and severe functional limitation.

Table 5 presents the results in the form of odds ratios. The effects of age and income are fairly consistent regardless of the outcome. Specifically, higher age increases the odds of a limitation, and respondents who are somewhat satisfied and, more so, those who are not satisfied with their income are more likely to report ADL limitations than are those satisfied with their income. Those with missing information on the income variable, 
who are likely to be unable to answer the question because of severe mental or other health problems, are the most likely to report limitations.

Other results are less likely to be statistically significant, yet generally confirm the hypotheses. Women, those not married, and those in rural areas of Cambodia are more likely than others to report a limitation, other things being equal. Marital status has the strongest influence on dressing, a task for which married individuals may receive help from their spouse. Rural residence exerts its strongest influence on bathing limitation. Indeed, bathing facilities may be much more modern and easier to negotiate among those living in urban Phnom Penh than in the other provinces. As for literacy, the results are least confirming. Those who are semi-literate are more likely to report any limitation and problems getting up from a lying position than are those who are literate, but results comparing the illiterate to the literate are insignificant across the models. It is difficult to speculate why literacy has such a minimal association with ADL limitation, although possible reasons include selection effects, where the illiterate are less likely to live to old age. On balance, however, the direction of associations and the number of statistically significant findings suggest that associations between these variables and functional limitation are similar in Cambodia to associations found in other settings.

\section{CONCLUSION}

Cambodia has emerged from a long period of conflict and violence during which the country was isolated from the rest of the world. Only recently have data become available with which to examine the health conditions of its citizens. The current analysis employed a very recent dataset to assess functional status using activities of daily living and basic demographic correlates of functional limitation among older Cambodians. ADLs represent a suitable vehicle for an investigation of health status since they are common measures, they comment on the functionality of the older population, and they assess the ability to conduct usual and necessary daily tasks within a social environment. As such, ADLs are an indicator not only of functional limitation but also of physical and social need. The analysis also examined active life expectancy, which combines information on functionality with information on mortality and allows for projections of the functional expectations of the population.

In many ways, the results conform to presumptions. For instance, women and older individuals are more likely to report functional limitations than are men and younger individuals. At age 60-64, only about 2 percent of men report a severe limitation compared to about 6 percent of women. By age 80, about one-third of men report any limitation (moderate or severe) compared to about one-half of women. Those not married, those living in rural areas, and those with lower levels of socioeconomic status, the last measured according to level of literacy and satisfaction with income, are generally more likely than others to report limitations, although the measure of literacy is not as closely linked to ADL items as might be expected.

Analysis of ALE showed that women live longer than men, with the extra years of life being spent in states of both moderate and severe limitation. Moreover, as older Cambodians age, they can expect to spend a greater percent of their remaining years with 
ADL limitation, and a greater proportion of inactive or functionally limited years suffering from severe limitation. As an example, women aged 60-64 can expect to live an additional 17.04 years, 12.15 without any limitation, 2.81 with moderate limitation, and 2.08 with severe limitation. Women aged 80 and older can expect 6.08 more years of life, with only 2.91 of those being active or without any limitation, 1.58 with moderate limitation, and 1.59 with severe limitation. This means that the proportion of life spent with a functional limitation as measured by ADLs is 29 percent for 60-64-year-old women and 52 percent for women aged 80 and older, while the proportion of inactive or functionally limited life spent with severe limitation is 43 percent for women 60-64 years old and 50 percent for women aged $80+$.

I compared ADL items from the Cambodian sample with items collected from surveys conducted in other Southeast Asian countries. Direct comparisons are always difficult given differences in culture, language, interpretation of survey items, survey administration, and question wording. Nevertheless, the results show substantially higher prevalence rates in Cambodia versus Burma, Indonesia, and Thailand, and moderately higher rates versus the Philippines. Several previous calculations of ALE have been conducted elsewhere in Southeast Asia (Saito, Qiao, and Jitapunkul 2003). These comparisons are even more tenuous since some of the items used to define the active state differed from those in the current study. But it is worth noting that estimates of ALE provided by Lamb (1999), which used ability to eat, dress, groom, walk, get out of bed, and bathe as items to measure an active state, reveal that elderly Cambodians live a substantially greater percent of their remaining years in a functionally limited state than do the elderly in Indonesia, North Korea, and Thailand and a moderately greater percent than those in Burma and Sri Lanka.

Is it reasonable that older Cambodians suffer from higher rates of functional limitation and have lower ALE than their counterparts in other Southeast Asian countries? Precise comparisons would require a much more extensive set of functional status items, which might include more objective measures such as physical performance tests. If elderly Cambodians are indeed more functionally limited, however, several possible reasons may be noted. First, no other country in the region has experienced the degree and type of social disruption that Cambodia has experienced. Previous research, cited earlier, suggested a number of ways in which war and social disruption lead to negative health outcomes. Second, with respect to many indicators, Cambodia is more underdeveloped than other countries in the region. For instance, Cambodia has a lower GNP and literacy rate than all other Southeast Asian countries with the exception of Laos (Population Reference Bureau 2004). To the degree that socioeconomic development is related to health outcomes-for instance, through the delivery of health services-Cambodia could be disadvantaged in comparison to its neighbors in the region. Third, measures of functional limitation used for the current study incorporate aspects of the social setting. Limitations in ability to carry out activities of daily living are determined both by physical abilities and by the demands of the environment (Verbrugge and Jette 1994). Environmental barriers that elderly Cambodians contend with, such as those related to impoverished living conditions and lack of household amenities, may make it more difficult for them to conduct usual and necessary daily 
activities in comparison to the elderly living elsewhere. Consistent with this notion, this study showed that functional limitations are less frequent among the elderly living in urban areas, where housing and other facilities tend to be more modern.

The main contribution of the current study is the reporting of a basic measure of health among a population about which little is known. Further work is necessary to fully define the health status of Cambodians, identify the determinants of health in the country, and place the health environment within a larger regional framework. I earlier cited a WHO orientation that conceptualized disability as caused by physical and mental impairments, which are in turn the consequences of particular diseases. Examination of impairments and disease status would undoubtedly help to inform the issue. Another area of inquiry is suggested by the trends in functional limitation by age revealed in the current study, which were found to be relatively linear, with curious variations occurring among those aged 75-79. Variation in the linear trend may be a function of sampling error, although it raises questions about possible links between historical circumstance and health outcomes. It is possible, for instance, that certain age cohorts were differentially influenced by earlier life conditions related to Cambodia's violent history and the accompanying epidemiological conditions. Research examining these long-term effects on health outcomes would obviously be useful for understanding determinants of health at older ages in regions of the world characterized by instability and for guiding policy and planning in these regions. 


\section{REFERENCES}

Agudelo, Saul Franco (1992). "Violence and Health: Preliminary Elements for Thought and Action.” International Journal of Health Services 22(2): 365-76.

Andrews, Gary R. n.d. Ageing in Southeast Asia: A Five Country Study. Report issued by the Australia Flinders Center for Aging Studies, Adelaide, Australia.

Annear, Peter (1998). "Health and Development in Cambodia." Asian Studies Review 22(2): 193-221.

Butera, J. B., Frere Johan Bultinck, and Pierre Mercier (1999). "The Rwandan Family Facing Survival: the Psychiatric Repercussions of the War." International Congress Series 1179: 193-98.

Chan, Sucheng (2004). Survivors: Cambodian Refugees in the United States. University of Illinois Press, Chicago.

Chandler, David (2000). A History of Cambodia. Westview Press, Boulder.

Chayovan, Napaporn and John Knodel. 1997. A Report on the Survey of the Welfare of the Elderly in Thailand. Bangkok, Thailand: Chulalongkorn University.

Crimmins, Eileen M., Mark D. Hayward, and Yasuhiko Saito (1996). "Differentials in Active Life Expectancy in the Older Population of the United States." Journal of Gerontology: Social Sciences. 51B(3): 111-20.

Deeg, Dorly J. H., Lois M. Verbrugge, and Carol Jagger (2003). "Disability Measurement." in J. M. Robine, C. Jagger, C.D. Mathers, E.M. Crimmins, and R.M. Suzman (eds), Determining Health Expectancies. John Wiley \& Sons, Hoboken, NJ, pp 203-20.

Ea, Meng-Try. (1981) "Kampuchea: A Country Adrift." Population and Development Review 7(2): 209-28.

Farhood, Laila, Huda Zurayk, Monique Chaya, Fadia Saadeh, Garbis Meshefedjian, and Thuraya Sidani (1993). "The Impact of War on the Physical and Mental Health of the Family: the Lebanese Experience." Social Science and Medicine 36(12): 155567.

Gillanders, W. R., Terry F. Buss, and C. Richard Hofstetter (1996). "Urban/Rural Elderly Health Status Differences: The Dichotomy Reexamined." Journal of Aging and Social Policy 8(4): 7-24.

Harpham, T., H. Reed, M. Montgomery, D. Satterhwaite, C. Moser, and B. Cohen (2003). "Mortality and Morbidity: Is City Life Good for Your Health?" in Mark R. 
Montgomery, Richard Stren, Barney Cohen, and Holly E. Reed (eds), Cities Transformed: Demographic Change and Its Implications in the Developing World. National Academies Press, Washington, pp 259-99.

Heuveline, Patrick (1998). “Between One and Three Million': Towards the Demographic Reconstruction of a Decade of Cambodian History: 1970-79." Population Studies 52: 49-65.

House, James S., R. C. Kessler, A. R. Herzog, A. M. Kinney, R. P. Mero, and M. F. Breslow (1990). "Age, Socioeconomic Status and Health." The Milbank Quarterly 68(3): 383-411.

Huguet, Jerrold W. (1991). "The Demographic Situation in Cambodia." Asia-Pacific Population Journal 6(4): 79-91.

Huguet, Jerrold W., Aphichat Chamratrithirong, Nott Ramma Rao, and San Sy Than (2000). "Results of the 1998 Population Census in Cambodia." Asia-Pacific Population Journal 15(3): 3-22.

Ityavyar, Dennis A., and Leo O. Ogba (1989). "Violence, Conflict and Health in Africa." Social Science and Medicine 28(7): 649-57.

Jagger, Carol (1999). "Health Expectancy Calculations by the Sullivan Method: A Practical Guide." Nihon University Population Research Institute Research Paper Series No. 68, Tokyo, Japan.

Kaplan, George A. (1992) "Health and Aging in the Alameda County Study." in K. W. Schaie, D. Blazer, and J. S. House (eds), Aging, Health Behavior and Health Outcomes. Lawrence Erlbaum Associates, Hillsdale, New Jersey, pp 69-88.

Kato, Elizabeth Uphoff (2000) "Ageing in Cambodia: Tradition, change and challenges" in David R. Phillips, (ed), Ageing in the Asia-Pacific Region. Routledge, New York, pp 360-374.

Katz, S., A. B. Ford, R. W. Moskowitz, B. A. Jackson, and M. W. Jaffee (1963). "Studies of Illness in the Aged: The Index of ADL, a Standardized Measure of Biological and Psychosocial Function." Journal of the American Medical Association 185: 914-19.

Katz, S., L.G. Branch, M.H. Branson, J.H. Papsidero, J.C. Beck, D.S. Greer (1983) “Active Life Expectancy." New England Journal of Medicine 309: 1218-1224.

Kiernan, Ben (2003). "The Demography of Genocide in Southeast Asia: the Death Tolls in Cambodia, 1975-79, and East Timor, 1975-80." Critical Asian Studies 35(4): 58597. 
(2002). "Introduction: Conflict in Cambodia, 1945-2002." Critical Asian Studies 34(4): 483-95.

(1996). The Pol Pot Regime: Race, Power and Genocide in Cambodia Under the Khmer Rouge, 1975-1979. Chiang Mai: Silkworm.

Knodel, J.E., S.K. Kim, Z.S. Zimmer, and S. Puch (2005) "Older persons in Cambodia: A profile from the 2004 Survey of Elderly." PSC Research Report 05-576.

Kola, Khieu (2004). "Fighting Poverty in Cambodia." The Contemporary Review 284(1658): 164-66.

Laditka, Sarah B., and Mark D. Hayward (2003). "The Evolution of Demographic Methods to Calculate Health Expectancies." in Jean-Marie Robine, Carol Jagger, Colin D. Mathers, Eileen M. Crimmins, and Richard M. Suzman (eds), Determining Health Expectancies. John Wiley \& Sons, Hoboken, NJ, pp 221-234.

Lamb, Vicki L. (1999). "Active Life Expectancy of the Elderly in Selected Asian Countries." Nihon University Population Research Institute Research Paper Series No. 69, Tokyo, Japan.

Lanjouw, Steven, Joanna Macrae, and Anthony B. Zwi (1999). "Rehabilitating Health Services in Cambodia: the Challenge of Coordination in Chronic Political Emergencies." Health Policy and Planning 14(3): 229-42.

Lawton, M. P., and E. Brody (1969). "Assessment of Older People: Self-Maintaining and Instrumental Activities of Daily Living." The Gerontologist 9(3): 179-86.

Manton, Kenneth G. (1989). "Epidemiological, Demographic and Social Correlates of Disability Among the Elderly." Milbank Memorial Fund Quarterly 67(Supplement 2, Part 1): 13-58.

Mathers, Colin D. (2002). "Health Expectancies: An Overview and Critical Appraisal." in Christopher J. L. Murray, Joshua A. Salomon, Colin D. Mathers, and Alan D. Lopez (eds), Summary Measures of Population Health: Concepts, Ethics, Measurement and Applications. World Health Organization, Geneva, pp 177-204.

Melzer, David, Grant Izmirlian, Suzanne G. Leveille, and Jack M. Guralnik (2001). "Educational Differences in the Prevalence of Mobility Disability in Old Age: The Dynamics of Incidence, Mortality, and Recovery." Journal of Gerontology: Social Sciences 56B(5): S294-S301.

Mollica, Richard F., Karen Donelan, Svang Tor, James Lavelle, Christopher Elias, Martin Frankel, and Robert J. Blendon (1993). "The Effect of Trauma and Confinement on Functional Health and Mental Health Status of Cambodians Living in Thailand- 
Cambodia Border Camps." Journal of the American Medical Association 270(5): 581-86.

National Institute of Statistics (1997). Cambodia Socioeconomic Survey 1997: Technical Report on Survey Design and Implementation. National Institute of Statistics, Phnom Penh.

National Institute of Statistics, Directorate General for Health [Cambodia], and ORC Macro (2000). Cambodia Demographic and Health Survey 2000. National Institute of Statistics, Directorate General for Health, Phnom Penh, Cambodia and Calverton, Maryland.

National Institute of Statistics, Ministry of Planning, Center for Population Studies, and Royal University of Phnom Penh (2004). First Revision Population Projections for Cambodia, 1998-2020. Phnom Penh: UNFPA.

Natividad, Josefina N. and Grace T. Cruz. (1997). "Patterns in Living Arrangements and Familial Support for the Elderly in the Philippines." Asia-Pacific Population Journal 12(4):17-34.

Neupert, Ricardo F., and Virak Prum (2003). "Cambodia: Reconstructing the Demographic Stab of the Past and Forecasting the Demographic Scar of the Future." Paper Presented at the IUSSP Seminar on the Demography of Conflict and Violence, Oslo, Norway, November 8-11.

Ott, Marvin C. (1997) "Cambodia: Between Hope and Despair." Current History 96(614): 431-36.

Pedersen, Duncan (2002). "Political Violence, Ethnic Conflict, and Contemporary Wars: Broad Implications for Health and Social Well-Being." Social Science and Medicine 55(2): 175-90.

Pol, Louis G., and Richard K. Thomas (1992). The Demography of Health and Health Care. Plenum Press, New York.

Population Reference Bureau (2004). 2004 World Population Data Sheet. PRB, Washington, DC.

Preston, Samuel H., and Paul Taubman (1994). "Socioeconomic Differences in Adult Mortality and Health Status." in Linda G. Martin and Samuel H. Preston (eds), Demography of Aging. National Academy Press, Washington.

Rogers, Richard G., Andrei Rogers, and Alain Belanger (1992). "Disability-Free Life Among the Elderly in the United States: Sociodemographic Correlates of Functional Health." Journal of Aging and Health 4(1): 19-42. 
Saito, Yasuhiko, Eileen M. Crimmins, and Mark D. Hayward (1999). Health Expectancy: An Overview. NUPRI Research Paper Series, No. 67. Nihon University Population Research Institute, Tokyo.

Saito, Yasuhiko, Xiaochun Qiao, and Sutthichai Jitapunkul (2003). "Health Expectancy in Asian Countries." in Jean-Marie Robine, Carol Jagger, Colin D. Mathers, Eileen M. Crimmins, and Richard M. Suzman (eds), Determining Health Expectancies. John Wiley \& Sons, Hoboken, NJ, pp 289-218.

Schwab, John J., John F. Ice, Judith J. Stephenson, Kathy Raymer, Kris Houser, Lisa Graziano, Paul Winkler, and Diane S. Eiland (1995). "War and the Family." Stress Medicine 11: 131-37.

Strawbridge, William J., George A. Kaplan, Terry Camacho, and Richard D. Cohen (1992). "The Dynamics of Disability and Functional Change in an Elderly Cohort: Results from the Alameda County Study." Journal of the American Geriatrics Society 40(8):799-806.

Sullivan, Daniel F. (1971) “A Single Index of Mortality and Morbidity." American Journal of Public Health 86(4): 347-54.

Ung, Loung (2000) First They Killed My Father. Harper Collins, New York, NY.

Verbrugge, Lois M., and Alan M. Jette (1994). “The Disablement Process.” Social Science and Medicine 38(1): 1-14.

Verheij, Robert A. (1996) "Explaining Urban-Rural Variations in Health: A Review of Interactions Between Individual and Environment." Social Science and Medicine 42(6): 923-35.

World Health Organization (1990). "The Composite International Diagnostic Interview" Version 1.0.

Zimmer, Zachary, Josefina N. Natividad, Mary Beth Ofstedal, and Hui-Sheng Lin (2002). "Physical and Mental Health of the Elderly." in Albert I. Hermalin (ed) The WellBeing of the Elderly in Asia: A Four-Country Comparative Study, University of Michigan Press, Ann Arbor, MI, Pp 362-416. 
Table 1: Description of sample of elderly Cambodians

\begin{tabular}{lcccc}
\hline & Total population & Males & Females & P-Value $^{\text {a }}$ \\
\hline $\mathrm{N}$ & 1273 & 512 & 761 & \\
Mean Age & 68.8 & 68.5 & 68.9 & .981 \\
& & & & \\
\% Not married & 48.7 & 18.4 & 69.1 & .000 \\
\% Rural & & & & \\
& 9.4 & 7.4 & 10.8 & .045 \\
Literacy & & & & \\
- \% Illiterate & 59.2 & 27.7 & 80.4 & .000 \\
- \% Semi-literate & 22.1 & 33.0 & 14.7 & \\
- \% Literate & 18.7 & 39.3 & 4.9 & \\
& & & & \\
Income Satisfaction & & & & \\
- \% Not satisfied & 22.1 & 21.2 & 22.7 & .586 \\
- \% Somewhat satisfied & 52.1 & 52.6 & 51.8 & \\
- \% Satisfied & 22.8 & 23.8 & 22.1 & \\
- \% Missing & 3.0 & 2.3 & 3.4 & \\
\hline
\end{tabular}

a Tests difference between males and females. 
Table 2: Percent reporting ADL limitations in Cambodia compared to other surveys from Southeast Asia

\begin{tabular}{llllll}
\hline & Cambodia & Burma $^{\mathrm{b}}$ & Indonesia $^{\mathrm{b}}$ & Philippines $^{\mathrm{c}}$ & Thailand $^{\mathrm{a}}$ \\
\hline $\begin{array}{l}\text { Getting up from lying } \\
\text { down }\end{array}$ & 18.8 & $7.8^{\mathrm{e} * * *}$ & $3.8^{\mathrm{e} * * *}$ & na & na \\
Eating & 8.7 & $5.4^{* * *}$ & $3.1^{* * *}$ & $4.5^{* * *}$ & $3.7^{* * *}$ \\
Bathing & 8.4 & $6.4^{* *}$ & $3.0^{* * *}$ & $7.2^{\mathrm{d}}$ & $6.2^{\mathrm{d} * * *}$ \\
Dressing & 6.2 & $5.0^{*}$ & $2.2^{* * *}$ & 5.9 & $3.2^{* * *}$ \\
At least one limitation & 23.0 & $10.5^{* * *}$ & $5.6^{* * *}$ & $9.0^{* * *}$ & $7.6^{* * *}$ \\
\hline
\end{tabular}

$* * * \mathrm{p}<.01 * * \mathrm{p}<.05 * \mathrm{p}<.10$ when comparing proportion versus Cambodia

a From 1995 data reported in Chayovan and Knodel (1997).

b From World Health Organization's 1989 survey of Health and Social Aspects of Ageing in Southeast Asia (Andrews n.d.).

c. From the 1996 Philippine Elderly Survey (see Natividad and Cruz 1997).

$\mathrm{d}$ Bathing and toileting are combined.

e Question asked about getting up from bed. 
Table 3: Percent reporting ADL limitations by age and sex

\begin{tabular}{|c|c|c|c|c|c|c|}
\hline & $\mathrm{N}$ & $\begin{array}{l}\text { At } \\
\text { least } \\
\text { one }\end{array}$ & $\begin{array}{l}\text { Getting } \\
\text { up }\end{array}$ & Eating & Bathing & Dressing \\
\hline \multicolumn{7}{|c|}{ Limitation of any severity } \\
\hline $\begin{array}{l}\text { Total } \\
\text { population }\end{array}$ & 1273 & 23.0 & 18.8 & 8.7 & 8.4 & 6.2 \\
\hline Men & 512 & 19.1 & 15.3 & 7.2 & 7.2 & 5.9 \\
\hline Women & 761 & 25.8 & 21.2 & 9.8 & 9.1 & 6.4 \\
\hline \multicolumn{7}{|l|}{ Age } \\
\hline $60-64$ & 418 & 11.7 & 9.3 & 4.6 & 2.9 & 1.5 \\
\hline $65-69$ & 337 & 21.7 & 17.4 & 6.6 & 3.9 & 3.3 \\
\hline $70-74$ & 294 & 30.9 & 25.9 & 14.7 & 10.6 & 8.7 \\
\hline $75-79$ & 149 & 29.5 & 26.1 & 9.4 & 12.6 & 10.1 \\
\hline $80+$ & 104 & 44.2 & 32.7 & 16.4 & 32.0 & 23.3 \\
\hline \multicolumn{7}{|c|}{ Severe limitation } \\
\hline $\begin{array}{l}\text { Total } \\
\text { population }\end{array}$ & 1273 & 9.3 & 7.3 & 3.6 & 3.1 & 2.4 \\
\hline Men & 512 & 7.4 & 5.5 & 2.9 & 2.5 & 2.0 \\
\hline Women & 761 & 10.6 & 8.5 & 4.1 & 3.6 & 2.6 \\
\hline \multicolumn{7}{|l|}{ Age } \\
\hline $60-64$ & 418 & 3.4 & 2.6 & 1.7 & 0.7 & 1.0 \\
\hline $65-69$ & 337 & 7.4 & 5.6 & 2.1 & 0.6 & 0.3 \\
\hline $70-74$ & 294 & 14.0 & 10.5 & 7.5 & 5.3 & 3.4 \\
\hline $75-79$ & 149 & 13.4 & 10.7 & 2.7 & 5.3 & 3.4 \\
\hline $80+$ & 104 & 22.3 & 19.2 & 8.7 & 12.6 & 10.7 \\
\hline
\end{tabular}


Figure 1: Percent reporting any ADL limitation and any severe limitation by age and sex

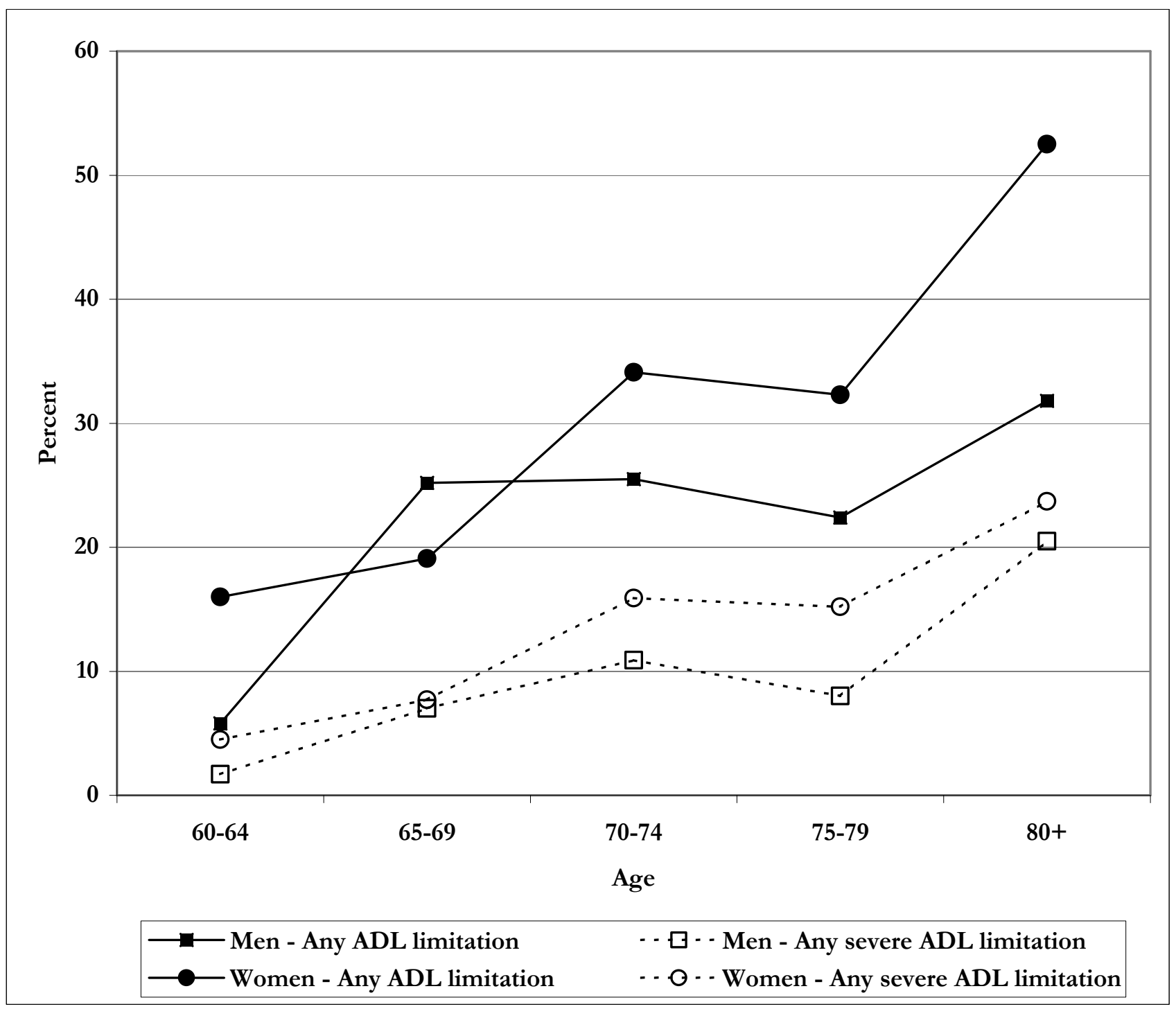


Table 4: Active life expectancy estimates by age and sex, with $95 \%$ confidence intervals in parentheses

\begin{tabular}{|c|c|c|c|c|c|c|}
\hline & Age & $\begin{array}{l}\text { Total life } \\
\text { expectancy }\end{array}$ & $\begin{array}{l}\text { Expected } \\
\text { life without } \\
\text { limitation }\end{array}$ & $\begin{array}{c}\text { Expected } \\
\text { life without } \\
\text { severe } \\
\text { limitation }\end{array}$ & $\begin{array}{l}\text { Expected } \\
\text { life with } \\
\text { limitation }\end{array}$ & $\begin{array}{l}\text { Expected } \\
\text { life with } \\
\text { severe } \\
\text { limitation }\end{array}$ \\
\hline \multirow[t]{5}{*}{ Men } & $60-64$ & 15.02 & $\begin{array}{c}11.87 \\
(12.45-11.29)\end{array}$ & $\begin{array}{c}13.77 \\
(14.18-13.37)\end{array}$ & $\begin{array}{c}3.15 \\
(2.73-2.57)\end{array}$ & $\begin{array}{c}1.25 \\
(1.65-0.84)\end{array}$ \\
\hline & $65-69$ & 11.99 & $\begin{array}{c}9.00 \\
(9.62-8.39)\end{array}$ & $\begin{array}{c}10.78 \\
(11.22-10.34)\end{array}$ & $\begin{array}{c}2.99 \\
(3.61-2.37)\end{array}$ & $\begin{array}{c}1.21 \\
(1.65-0.77)\end{array}$ \\
\hline & $70-74$ & 9.30 & $\begin{array}{c}6.53 \\
(7.21-5.86)\end{array}$ & $\begin{array}{c}8.15 \\
(8.64-7.66)\end{array}$ & $\begin{array}{c}2.77 \\
(3.44-2.10)\end{array}$ & $\begin{array}{c}1.16 \\
(1.65-0.67)\end{array}$ \\
\hline & $75-79$ & 7.06 & $\begin{array}{c}4.54 \\
(5.30-3.78)\end{array}$ & $\begin{array}{c}5.97 \\
(6.54-5.39)\end{array}$ & $\begin{array}{c}2.52 \\
(3.28-1.77)\end{array}$ & $\begin{array}{c}1.10 \\
(1.67-0.52)\end{array}$ \\
\hline & $80+$ & 5.31 & $\begin{array}{c}3.03 \\
(3.88-2.17)\end{array}$ & $\begin{array}{c}4.26 \\
(4.95-3.57)\end{array}$ & $\begin{array}{c}2.28 \\
(3.14-1.42)\end{array}$ & $\begin{array}{c}1.05 \\
(1.73-0.36)\end{array}$ \\
\hline \multirow[t]{5}{*}{ Women } & $60-64$ & 17.04 & $\begin{array}{c}12.15 \\
(12.69-11.62)\end{array}$ & $\begin{array}{c}14.96 \\
(15.37-14.55)\end{array}$ & $\begin{array}{c}4.89 \\
(5.43-4.35)\end{array}$ & $\begin{array}{c}2.08 \\
(2.49-1.68)\end{array}$ \\
\hline & $65-69$ & 13.63 & $\begin{array}{c}9.09 \\
(9.64-8.55)\end{array}$ & $\begin{array}{c}11.65 \\
(12.07-11.22)\end{array}$ & $\begin{array}{c}5.54 \\
(5.09-3.99)\end{array}$ & $\begin{array}{c}1.99 \\
(2.41-1.56)\end{array}$ \\
\hline & $70-74$ & 10.62 & $\begin{array}{c}6.50 \\
(7.07-5.94)\end{array}$ & $\begin{array}{c}8.75 \\
(9.21-8.30)\end{array}$ & $\begin{array}{c}4.12 \\
(4.68-3.55)\end{array}$ & $\begin{array}{c}1.87 \\
(2.32-1.41)\end{array}$ \\
\hline & $75-79$ & 8.09 & $\begin{array}{c}4.45 \\
(5.06-3.83)\end{array}$ & $\begin{array}{c}6.36 \\
(6.88-5.84)\end{array}$ & $\begin{array}{c}3.65 \\
(4.27-3.03)\end{array}$ & $\begin{array}{c}1.73 \\
(2.25-1.21)\end{array}$ \\
\hline & $80+$ & 6.08 & $\begin{array}{c}2.91 \\
(3.66-2.16)\end{array}$ & $\begin{array}{c}4.48 \\
(5.14-3.82)\end{array}$ & $\begin{array}{c}3.17 \\
(3.92-2.42)\end{array}$ & $\begin{array}{c}1.59 \\
(2.25-0.93)\end{array}$ \\
\hline
\end{tabular}


Figure 2: Percent of remaining life spent in various states of functional limitation by age and sex

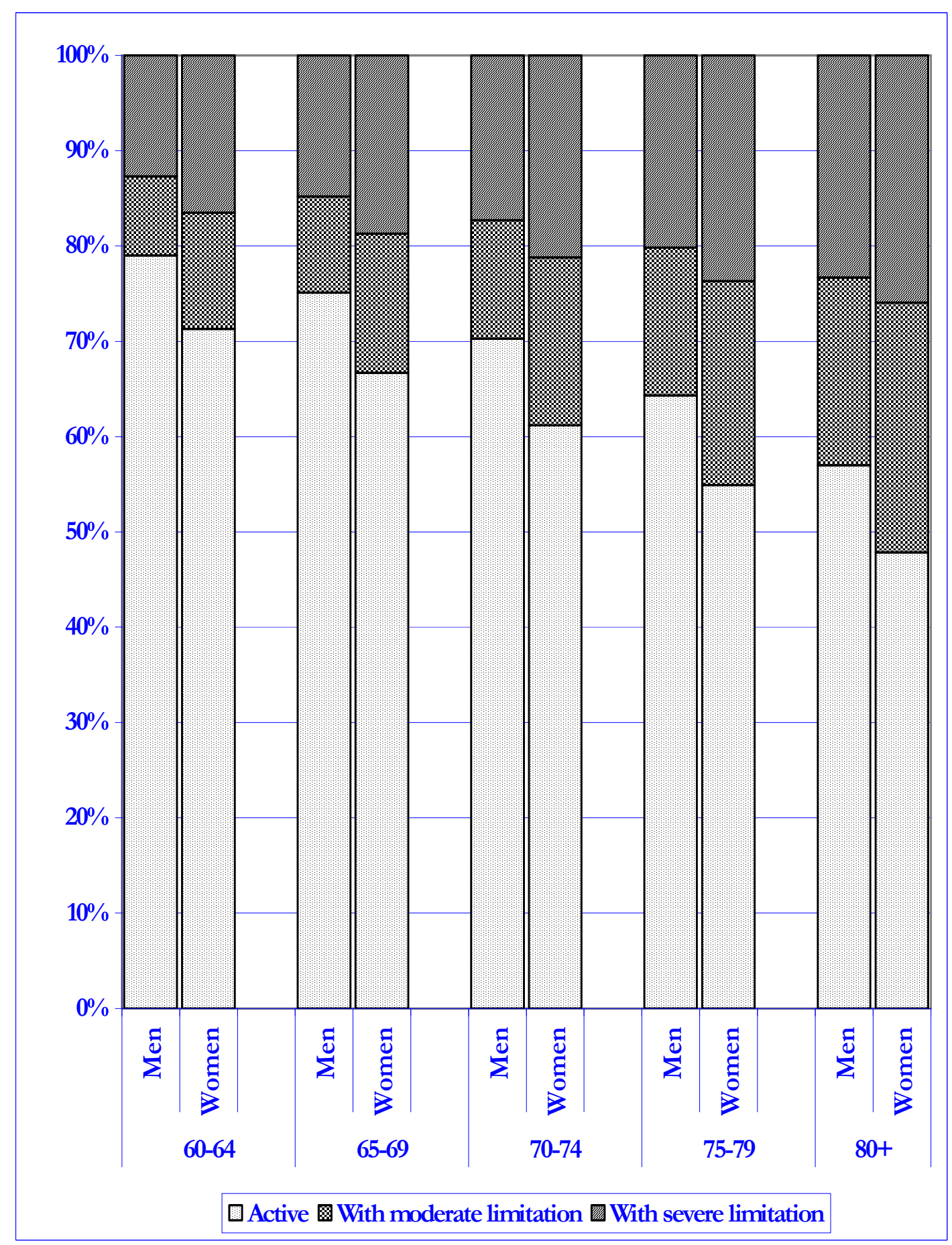


Table 5: Logistic regression results predicting any, severe, and task-specific limitation

\begin{tabular}{|c|c|c|c|c|c|c|}
\hline & Any limitation & $\begin{array}{l}\text { Any severe } \\
\text { limitation }\end{array}$ & Getting up & Eating & Bathing & Dressing \\
\hline Age & $1.074 * * *$ & $1.076^{* * *}$ & $1.067 * * *$ & $1.045 * * *$ & $1.114 * * *$ & $1.100 * * *$ \\
\hline Female (vs. male) & $1.541^{*}$ & 1.749 & $1.682 *$ & 1.173 & 1.036 & 0.673 \\
\hline Not married (vs. married) & 1.197 & 1.052 & 1.074 & $1.664 * * *$ & $1.629 *$ & $2.523 * * *$ \\
\hline Rural residence (vs. urban) & $1.569 * *$ & 1.189 & $1.643^{*}$ & 1.156 & $2.002 * * *$ & 1.705 \\
\hline \multicolumn{7}{|l|}{ Literacy (vs. literate) } \\
\hline - Semi-literate & $1.590 * * *$ & 0.829 & $1.631 * * *$ & 1.283 & 0.877 & 1.009 \\
\hline - Illiterate & 0.987 & 0.698 & 0.985 & 0.917 & 1.012 & 1.203 \\
\hline \multicolumn{7}{|c|}{ Income satisfaction (vs. satisfied) } \\
\hline - Somewhat satisfied & 1.323 & $2.197 * *$ & 1.246 & $2.330 * *$ & $1.905^{* *}$ & 1.637 \\
\hline - Not satisfied & $2.438 * * *$ & $2.726 * * *$ & $2.073 * * *$ & 1.517 & $2.574 * * *$ & 1.747 \\
\hline - Missing information & $3.836^{* * *}$ & $8.364 * * *$ & $3.208 * * *$ & $6.107 * * *$ & $6.690 * * *$ & $5.362 * * *$ \\
\hline Model $\chi^{2}$ & $342.2 * * *$ & $376.9 * * *$ & $243.9^{* * *}$ & $95.4 * * *$ & $185.9^{* * *}$ & $287.2^{* * *}$ \\
\hline
\end{tabular}

$* * * \mathrm{p}<.01 \quad * * \mathrm{p}<.05 \quad * \mathrm{p}<.10$

Note: Uses robust standard errors to adjust clustering by district. 


\section{POLICY RESEARCH DIVISION WORKING PAPERS}

If still in print, single copies of up to three working papers from 1989 through 2003 are available free of charge.

Beginning with the 2004 issues, working papers are no longer available in print format. Instead they are distributed electronically. As each new paper is completed subscribers are notified by e-mail and a link to the paper is provided.

To subscribe to the Policy Research Division working paper e-mail notification list, or to obtain back issues from 1989 to 2003, please send your request to prdwp@popcouncil.org.

PDFs of recent issues are available at www.popcouncil.org/publications/wp/prd/rdwplist.html

2005

201 Zachary Zimmer, “Active life expectancy and functional limitations among older Cambodians: Results from a 2004 survey."

200 Brian Wells Pence, Philomena Nyarko, James F. Phillips, and Cornelius Debpuur, "The effect of community nurses and health volunteers on child mortality: The Navrongo Community Health and Family Planning Project."

199 Zachary Zimmer, Linda G. Martin, Mary Beth Ofstedal, and Yi-Li Chuang, "Education of adult children and mortality of their elderly parents in Taiwan."

198 Mian Bazle Hossain, James F. Phillips, and Thomas K. LeGrand, "The impact of childhood mortality on fertility in six rural thanas of Bangladesh."
197 Kristine R. Baker, Mary Beth Ofstedal, Zachary Zimmer, Zhe Tang, and Yi-Li Chuang, "Reciprocal effects of health and economic well-being among older adults in Taiwan and Beijing."

196 Mark R. Montgomery and Paul C. Hewett, "Poverty and children's schooling in urban and rural Senegal."

2004

195 Luciana Suran, Sajeda Amin, Lopita Huq, and Kobita Chowdury, "Does dowry improve life for brides? A test of the bequest theory of dowry in rural Bangadesh."

194 Barbara S. Mensch, Monica J. Grant, Mary P. Sebastian, Paul C. Hewett, and Dale Huntington. "The effect of a livelihoods intervention in an urban slum in India: Do vocational counseling and training alter the attitudes and behavior of adolescent girls?" 
193 Amanda Ritchie, Cynthia B. Lloyd, and Monica Grant. "Gender differences in time use among adolescents in developing countries: Implications of rising school enrollment rates."

192 John Bongaarts. "Long-range trends in adult mortality: Models and projection methods."

191 John Koku Awoonor-Williams, Ellie S. Feinglass, Rachel Tobey, Maya N. Vaughan-Smith, Frank K. Nyonator, Tanya C. Jones, and James F. Phillips, "Bridging the gap between evidence-based innovation and national healthsector reform in Ghana."

190 Kelly Hallman, "Socioeconomic disadvantage and unsafe sexual behaviors among young women and men in South Africa."

189 Toshiko Kaneda, Zachary Zimmer, and Zhe Tang, "Differentials in life expectancy and active life expectancy by socioeconomic status among older adults in Beijing."

188 Cynthia B. Lloyd and Monica J. Grant, "Growing up in Pakistan: The separate experiences of males and females."

187 Zachary Zimmer, Xianghua Fang, Toshiko Kaneda, Zhe Tang, and Julia Kwong. "Trends and transitions in children's coresidence with older adults in Beijing municipality."
186 Sajeda Amin and Alaka M. Basu. "Popular perceptions of emerging influences on mortality and longevity in Bangladesh and West Bengal."

185 John Bongaarts. "Population aging and the rising cost of public pensions."

184 Mark R. Montgomery and Paul C. Hewett. "Urban poverty and health in developing countries: Household and neighborhood effects.

2003

183 Agnes R. Quisumbing and Kelly Hallman. "Marriage in transition: Evidence on age, education, and assets from six developing countries."

182 Paul C. Hewett, Barbara S. Mensch, and Annabel S. Erulkar, "Consistency in the reporting of sexual behavior among adolescent girls in Kenya: A comparison of interviewing methods."

181 Zachary Zimmer, Linda G. Martin, and Hui-Sheng Lin, "Determinants of old-age mortality in Taiwan."

180 Frank K. Nyonator, J. Koku Awoonor-Williams, James F. Phillips, Tanya C. Jones, and Robert A. Miller, "The Ghana Community-based Health Planning and Services Initiative: Fostering evidence-based organizational change and development in a resourceconstrained setting." 
179 John Bongaarts and Griffith

Feeney, "Estimating mean

lifetime."

178 Elizabeth F. Jackson, Patricia Akweongo, Evelyn Sakeah, Abraham Hodgson, Rofina Asuru, and James F. Phillips, "Women's denial of having experienced female genital cutting in northern Ghana: Explanatory factors and consequences for analysis of survey data."

177 John Bongaarts, "Completing the fertility transition in the developing world: The role of educational differences and fertility preferences."

176 Cynthia B. Lloyd and Paul C. Hewett, "Primary schooling in sub-Saharan Africa: Recent trends and current challenges."

175 James F. Phillips, Tanya C. Jones, Frank K. Nyonator, and Shruti Ravikumar, "Evidence-based development of health and family planning programs in Bangladesh and Ghana."

174 Geoffrey McNicoll, "Population and development: An introductory view."

173 Paul Demeny, "Population policy: A concise summary."

172 Zachary Zimmer, Napaporn Chayovan, Hui-Sheng Lin, and Josefina Natividad, "How indicators of socioeconomic status relate to physical functioning of older adults in three Asian societies."
171 Sajeda Amin and Nagah H. AlBassusi, "Wage work and marriage: Perspectives of Egyptian working women."

170 Ravai Marindo, Steve Pearson, and John B. Casterline, "Condom use and abstinence among unmarried young people in Zimbabwe: Which strategy, whose agenda?"

169 Zachary Zimmer and Julia Dayton, "The living arrangements of older adults in sub-Saharan Africa in a time of HIV/AIDS."

168 Paul C. Hewett, Annabel S. Erulkar, and Barbara S. Mensch, "The feasibility of computerassisted survey interviewing in Africa: Experience from two rural districts in Kenya." 